\title{
THE MANAGEMENT OF E-LEARNING
}

\author{
Alex Fung and Jenilyn Ledesma \\ With Abdelmalek Benzekri, Margaret Clarke, Celso Perdomo-Gonzalez, Jorge Rodriguez- \\ Diaz, and Harald Yndestad
}

Key words: E-learning, technology, teaching and learning

\section{PREAMBLE}

The discussion group explored and addressed several areas regarding the management of e-learning. Building on the discussion, six issues were identified at the end of the conference. These six issues have provided the structure for this discussion paper. Each issue is discussed separately.

\section{DEFINITIONS OF E-LEARNING}

The world of education has now moved into an era of e-learning, and the existence of technology has reached a point where it challenges the traditional education system. Keywords are highlighted in an attempt to define and discuss e-learning and its associated issues. These keywords include:

- Use of Internet / Intranet / Extranet

- Synchronous / Asynchronous

- Integration of Media Technology.

The following were some of the definitions of e-learning.

" $e$ " means electronic media to help enhance student education. It also means computer-mediated (based) learning, and can be both off campus (remote) as well as on campus (present). It is also about time and space. 
e-learning is a technologically driven education. It means computerassisted learning, with additional support from teachers, guides and utilizing learning objects.

From education to e-learning, the learning activities and roles change. In this digital era, there are new database technologies, new structures, new delivery modes, and new system concepts. Even the roles of teachers and students change. Teachers do not just teach; they coach, instruct and advise. Students do not just listen; they learn how to learn and how to be creative and proactive.

\section{VISIONS OF E-LEARNING [DREAMS FOR THE NEW EDUCATION SYSTEM]}

So, what change will occur after the introduction of e-learning? Some visions and dreams for the new education system are presented.

Dream 1: The Professor or 'teacher' comes to the class not to deliver knowledge, but to listen, discuss and share information and experiences with the students.

Dream 2: Education could either be group collaboration or individualized learning, or both. Learning becomes multidimensional, more customized and personalized, catering for the individual needs of learners and differences between learners.

Dream 3: To have equity or 'education for all learners'. Life-long and life-wide learning is about breadth and depth not restricted to the academic realm.

Dream 4: The final goal of e-learning - the creation, interaction and generation of knowledge, skills and competencies in learners.

\section{HOW TO GET THERE WITH THE SUPPORT OF TECHNOLOGY}

Utilizing technology has the potential to realize these dreams (new ways of learning). Change management is needed, including the management of change within the organization, changes to the roles of individuals, taking account of globalisation and social as well as structural changes. Integration and adaptation of technology into other sub-systems and parameters of education are also required (see Figure 15-1). Learning issues, either by self or by groups, need to be identified to better enhance e-learning. 


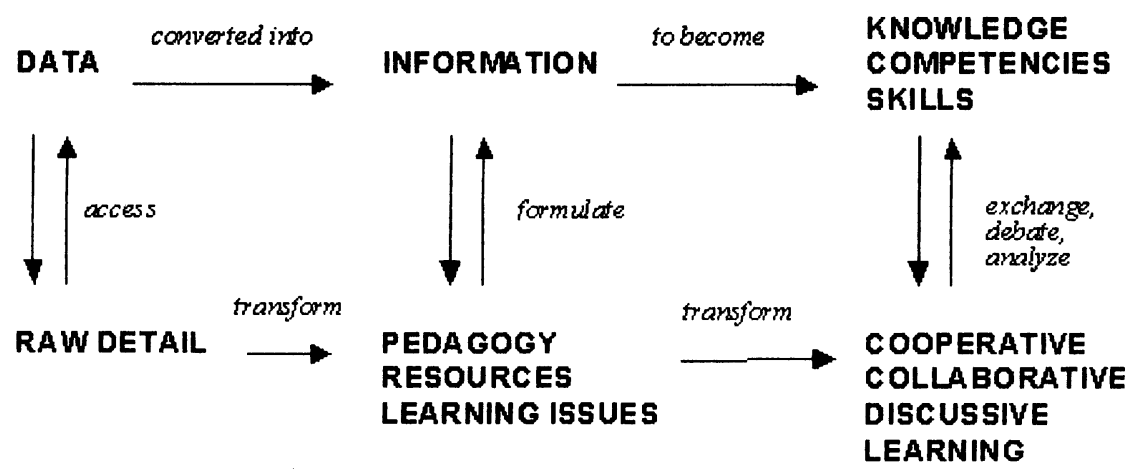

Figure 15.1. Integration and adaptation of technology into other sub-systems and parameters of education

Technology as an end it itself: is what we can refer to as learning technology: about systems of communication, parts of a computer, learning to use a text editor, navigating the Internet and so on.

Technology as a tool: corresponds to the conception most in use: doing practical things, allowing the technical operation of machines and the running of software.

Technology as a teaching resource: it can be used to look at subjects as diverse as mathematics and social studies, and also to reinforce as well as widen our knowledge of them.

\section{CHANGES NEEDED TO SUPPORT E-LEARNING}

Several changes are seen as necessary to support e-learning. Firstly, there is a need for standardization to assure inter- and intra-comparability. Education can take advantage of e-learning by preparing digitised materials/activities to be accessible on the Internet, which can be appropriately used as learning objects for the learners. Universities, schools and other institutions can become places for delivery, communication and interaction. There should be ongoing, dynamic evaluation by feedback. Freeware should be encouraged instead of commercial IT software packages, for equity to students accessing information anywhere anytime. Cultural and mindset changes are also needed, as well as the re-organization of technology for better delivery of learning. Customisation from a 'train system' (mass production) to a 'taxi system' (flexible) is required, although infrastructure and traffic should be considered. Teachers' roles should be 
more versatile and inventive. The role of educational institutions may be perceived to be as one that maintains and develop culture (cultural preservation and knowledge creation), but at the same time to contribute to the development of other areas (professional skills development, societal needs). Different sets of skills, dispositions and competences are necessary to help students respond to new content, new ideas and settings. In short, education and e-learning should be integral to education.

\section{DIFFERENT ROLES TO MAKE E-LEARNING OPERATIONAL}

To make e-learning operational, different availabilities and roles are presently required. People with passion to promote or "champion" the vision (dream) are needed.

- Teaching and learning: Collaborative learning vs. collaborative (team) teaching

- Roles: movers, shakers, visionaries, enforcers, advocators (preachers), educators, diffusers, developers, makers, creators, planners, actors

The potential threat of multi-national corporations dominating education should encourage educational institutions to cooperate, network and organize at different levels (public, private, schools, universities).

- School and university: the shift from the trains (too static and compartmentalized) to the taxi (flexible) system in education delivery is needed for a smooth and coherent progression from school and university to the workplace, and eventually for life long learning.

With the new actors / roles,

- Students change from passive receiver to protagonist of the process;

- Teachers possess important organizational skills, and stop being the source of information to become learning facilitators.

The presence of new demands in society will also continue the formation of new actors and roles, all of which will be actively participating in the promotion process, with the capacity and ability to modify the methodology applied to the teaching and learning paradigm from beginning to end.

\section{OTHER ISSUES AND POINTS TO PONDER}

New ways of thinking, although problematic, lead to new pedagogy. There is no doubt that the use of technology can better support this change. Not only do teachers and learners need to be adaptable but they also need to 
be more proactive. This adds value to the use of ICT in education. Hence, there is a need to re-invent and re-engineer the education system. But, how can one turn this process into something operational? What kind of organizations can give this endorsement?

IFIP is one organization that can help ensure that e-learning is given the consideration it merits e.g. in giving endorsements to these ideas, top down and/or bottom up action plans. Strategic channels are needed to raise the concern of different actors at different levels of this important aspect of education. 